\title{
Pelestarian Budaya Lokal melalui Edukasi Pengenalan Batik Tulis Khas Kabupaten Malang bagi Kelompok PKK
}

\author{
Aris Siswati, Alif Dewantara, Noeke Chrispur Madiarsih \\ Departemen Ekonomi Pembangunan, Fakultas Ekonomi dan Bisnis, Universitas Merdeka Malang, \\ Jl. Terusan Raya Dieng No.62-64, Malang, 65146, Indonesia
}

\begin{abstract}
ARTICLE INFO:
Received: 2020-08-09

Revised: 2020-09-12

Accepted: 2020-10-24
\end{abstract}

\section{Keywords:}

Culture; Education; Preserve local culture; Written batik

\section{ABSTRACT}

Batik is one of the original handicrafts of the Indonesian which is very well known for its beautiful motifs and is also full of various philosophical values. Efforts to preserve local culture, especially written batik, must be made in order to strengthen the Indonesian identity. One form of effort made is through education which aims to provide insight into the knowledge of batik. The participation of academics through their obligations to carry out community service becomes a bridge in these conservation. For this reason, the activities are carried out through an educational program on the introduction of batik, especially written batik typical of Malang to the empowerment of family welfare or PKK in Banjararum Village, Singosari, Malang Regency. The activity agreed upon between the service team and the PKK Banjararum was to provide insight into knowledge in the form of socialization to PKK about batik. The result of this activity is the increased awareness of the community about the importance of preserving the Indonesian nation's culture, especially batik which in turn creates awareness to use Indonesian original batik, creating ideas for a productive economic sector for the community by utilizing existing potential and human resources, and the sustainability of efforts to preserve the environment through culture.

(C) 2020 Published by University of Merdeka Malang. This is an open access article distributed under the CC BY-SA 4.0 license (https://creativecommons.org/licenses/by-sa/4.0/)

How to cite: Siswati, A., Dewantara, A., \& Madiarsih, N. C. (2020). Pelestarian Budaya Lokal melalui Edukasi Pengenalan Batik Tulis Khas Kabupaten Malang bagi Kelompok PKK. Abdimas: Jurnal Pengabdian Masyarakat Universitas Merdeka Malang, 5(3), 249-256. https://doi.org/10.26905/abdimas.v5i3.5037

\section{PENDAHULUAN}

Kerajinan batik merupakan salah satu jenis kerajinan asli bangsa Indonesia yang sudah sangat terkenal dengan keindahan motifnya dan juga sarat dengan berbagai nilai filosofi. Badan khusus PBB yaitu UNESCO bahkan telah mencanangkan batik sebagai warisan budaya dunia, tepatnya pada 2 Oktober 2009. Batik melalui keunikan motifnya menjadi penanda atau karakter yang merupakan simbol identitas dan jatidiri bangsa Indonesia (Farida, 2017) 
ABDIMAS: Jurnal Pengabdian Masyarakat Universitas Merdeka Malang

Volume 5, No 3, November 2020: 249-256

LPPM (Lembaga Penelitian dan Pengabdian Masyarakat) Universitas Merdeka Malang sebagai lembaga berbasis penelitian dan pengabdian kepada masyarakat telah menyusun Renstra (Rencana Strategis) 2016-2020 berdasarkan analisis lingkungan internal dan eksternal, isu utama pengembangan pendidikan tinggi yang berkaitan dengan pengabdian kepada masyarakat, yaitu pemberdayaan, entrepreneurship/ ekonomi kreatif, dan lingkungan. Ketiga isu dalam Renstra tersebutlah yang menjadi dasar akan dilaksanakan program pemberdayaan kepada masyarakat di Dusun Banjararum. Mengenai entrepreneurship bahwa kegiatan pengabdian ini diharapkan mampu menumbuhkan ide bagi masyarakat untuk mencoba peluang bisnis di bidang kerajinan batik tulis, dimana pengetahuan menjadi salah satu faktor yang mempengaruhi jiwa kewirausahaan (Siswati \& Prakoso, 2018). Bertambahnya jumlah penduduk yang diikuti dengan meningkatnya pendapatan masyarakat akan berpengaruh terhadap meningkatnya pajak daerah (Asy'ari et al. 2020). Kegiatan pemberdayaan masyarakat yang dilakukan akademisi akan membantu mengatasi permasalahan yang ada di masyarakat (Triatmanto et al., 2019). Salah satu contoh bentuk pendampingan yang dilakukan adalah tentang proses produk dan desain, perhitungan harga produksi dan metode pemasaran (Dwipasari \& Subianto, 2018). Pendampingan tersebut sebenarnya adalah merupakan pembelajaran yang berbasis pengalaman yang diistilahkan experiental center learning dimana peserta pembelajaran akan berproses mempelajari hal baru atau mengembangkan pengetahuan yang sudah dimiliki berdasar pengalaman yang pernah dialaminya atau pengalaman dari orang lain (Siswati, 2019). Pelatihan penerapan teknologi tepat guna juga merupakan metode pendampingan yang efektif dalam rangka pemberdayaan masyarakat (Andarwati et al., 2018). Selain kepada kelompok PKK, pelatihan batik juga efektif dilaksanakan untuk anak-anak mulai tingkat sekolah dasar dalam upaya mengembangkan bakat dan kreatifitas (Wardani, 2014)

Pengembangan motif dengan latar belakang seorang wanita atau ibu akan berpengaruh terhadap hasil akhir, dimana perasaan akan menjadi bagian yang diekspresikan dalam motif batik yang dihasilkan (Rahmadani, 2019). Motif lain juga bisa didapatkan dengan mengeksplorasi ragam keindahan alam, salah satu misalnya adalah ragam keindahan bawah laut (Bidayani, 2019). Selain batik tulis, terdapat jenis batik lain yang juga cukup populer di masyarakat yaitu berupa jumputan yang dapat juga disampaikan pada sebuah pelatihan untuk dikembangkan (Rahmanita et al., 2020). Beberapa pengrajin batik tulis berproduksi hanya apabila mendapat pesanan atau ada permintaan untuk pelaksanaan event saja (Jannah et al., 2020), hal ini dikarenakan profesi pengrajin batik hanya sebagai usaha sampingan karena wawasan masyarakat pada taraf ini belum sampai pada kesadaran diri melestarikan batik itu sendiri.

Tujuan yang dihasilkan dari kegiatan pengabdian ini adalah terciptanya kesadaran bagi masyarakat dalam upaya pelestarian budaya bangsa khususnya batik tulis yang berpotensi untuk berkembang menjadi sumber usaha keluarga, terbentuk komunitas masyarakat peduli budaya yang didalamnya mencakup kegiatan edukasi batik tulis, warga RT.14 RW.11 Desa Banjararum, Kecamatan Singosari, Kabupaten Malang sebagai mitra pengabdian menjadi contoh dan memotivasi warga sekitar yang lain untuk sadar budaya.

Singosari adalah salah satu kecamatan dari 33 Kecamatan yang ada di Kabupaten Malang. Kecamatan Singosari terdiri atas 14 Desa (Ardimulyo, Banjararum, Baturetno, Dengkol, Gunungrejo, Klampok, Lang-lang, Purwoasri, Randuagung, Tamanharjo, Toyomarto, Tunjungtirto, Watugede dan Wonorejo) dan 3 Kelurahan (Candirenggo, Losari dan Pagentan) dan secara administratif, Kecamatan ini berbatasan dengan (1) sebelah utara: Kecamatan Lawang; (2) Sebelah timur: Kecamatan Jabung; (3) Sebelah selatan: Kecamatan Blimbing, Kota Malang; (4) Sebelah barat: Kecamatan Karangploso. 


\section{Pelestarian Budaya Lokal melalui Edukasi Pengenalan Batik Tulis Khas Kabupaten Malang bagi Kelompok PKK}

Aris Siswati, Alif Dewantara, Noeke Chrispur Madiarsih

Kecamatan Singosari memiliki luas wilayah $14.876 \mathrm{Ha}$, berada pada ketinggian $487 \mathrm{mdpl}$ dengan suhu rata-rata antara 22 - 32 derajat Celcius. Kecamatan ini dilintasi oleh jalur utama Malang - Surabaya, yang pada saat belum dibangunnya jalan tol Malang-Pandaan jalan lintas utama ini merupakan jalur termacet pada hari-hari tertentu terutama pada saat libur panjang. Bersama dengan Kecamatan Lawang dan Kecamatan Kepanjen, Singosari dikenal sebagai kota satelit penyangga utama Kota Malang. Secara topografi wilayah Kecamatan Singosari berada di daerah dataran tinggi di kaki Gunung Arjuno, sehingga sebagian penduduknya bermata pencarian di bidang perkebunan, kehutanan dan peternakan. Letak yang strategis di pintu masuk Kota Malang, juga menjadi aset bagi wilayah ini dibuktikan dengan pesatnya perkembangan dunia industri. Banyak terdapat perusahaan-perusahaan besar yang mendirikan pabrik di Kecamatan Singosari. Salah satu yang menjadi alasan bagi pengusaha selain letaknya yang strategis adalah faktor keamanan wilayah. Di Kecamatan Singosari terdapat beberapa Markas Militer diantara Divisi 2 Infanteri Kostrad, YonArmed dan Yonkav 3./Tank. Bidang pendidikan juga tidak kalah menggeliat, dengan keberadaan sekolah-sekolah yang unggul baik negeri maupun swasta serta adanya beberapa pondok pesantren.

Lokasi mitra pengabdian berada di Dusun Banjararum, Kecamatan Singosari, kabupaten Malang. Desa Banjararum merupakan salah satu desa yang masuk wilayah Kecamatan Singosari, letaknya di bagian utara dari kecamatan Singosari. Desa ini terdiri dari 3 dusun, 14 RW dan 78 RT, yang wilayahnya terdiri dari beragam tipe pemukiman diantaranya terdapat perumahan real estate dan terdapat juga perumahan Polri. Selain itu terdapat juga beberapa sekolah dari tingkat TK sampai dengan SMA.

Undang-undang Nomor 20 Tahun 2003 tentang Sistem Pendidikan nasional Pasal 20 mengamanahkan bahwa Perguruan Tinggi berkewajiban menyelenggarakan penelitian dan pengabdian kepada masyarakat disamping melaksanakan pendidikan dan pengajaran. Sedangkan Undang-undang Nomor 12 Tahun 2012 tentang Pedidikan Tinggi Pasal 45 menegaskan bahwa penelitian di perguruan tinggi diarahkan untuk mngembangkan ilmu pengetahuan dan teknologi, serta meningkatkan kesejahteraan masyarakat dan daya saing bangsa. Dalam pasal tersebut juga ditegaskan bahwa pengabdian kepada masyarakat merupakan kegiatan sivitas akademika dalam mengamalkan dan membudayakan ilmu pengetahuan dan teknologi untuk memajukan kesejahteraan umum dan mencerdaskan kehidupan bangsa.

LPPM (Lembaga Penelitian dan Pengabdian Masyarakat) Universitas Merdeka Malang sebagai lembaga berbasis penelitian dan pengabdian kepada masyarakat telah menyusun Renstra (Rencana Strategis) 2016-2020 berdasarkan analisis lingkungan internal dan eksternal, isu utama pengembangan pendidikan tinggi yang berkaitan dengan pengabdian kepada masyarakat, yaitu pemberdayaan, entrepreneurship/ ekonomi kreatif dan lingkungan. kedua isu dalam Renstra tersebutlah yang menjadi dasar akan dilaksanakan program pemberdayaan kepada masyarakat di Dusun Banjararum.

Saat ini yang menjadi permasalahan di Dusun Banjararum terkait dengan kebudayaan Indonesia adalah kurangnya pengetahuan masyarakat mengenai salah satu hasil budaya asli bangsa Indonesia yaitu kerajinan batik tulis. Masyarakat Desa Banjararum perlu diberikan bekal edukasi mengenai batik tulis mencakup bagaimana proses pembuatan batik tulis, ragam jenis dan corak batik tulis Indonesia, daerah potensial penghasil batik tulis dan yang utama lagi adalah menyampaikan bahwa kerajinan batik tulis berpotensi untuk menjadi satu bentuk usaha yang bisa dilakukan masyarakat khususnya kaum ibu rumah tangga dalam rangka meningkatkan peran serta dalam perekonomian keluarga. Hal ini yang melatar 
ABDIMAS: Jurnal Pengabdian Masyarakat Universitas Merdeka Malang

Volume 5, No 3, November 2020: 249-256

belakangi Tim pengabdi dari perguruan tinggi untuk bersama-sama mengembangkan potensi sumberdaya manusia di Desa Banjararum melalui edukasi pengenalan batik tulis.

Kegiatan yang disepakati antara Tim dan masyarakat Desa Banjararum adalah memberikan wawasan pengetahuan dalam bentuk sosialisasi kepada ibu-ibu kelompok PKK Dusun Banjararum tentang batik tulis. Target dari kegiatan ini adalah meningkatnya kesadaran masyarakat tentang pentingnya pelestarian budaya bangsa Indonesia, terutama batik tulis yang pada akhirnya menciptakan kesadaran masyarakat untuk menggunakan produk batik tulis asli buatan Indonesia, terciptanya ide sektor ekonomi produktif bagi masyarakat dengan memanfaatkan potensi dan SDM yang ada, dan keberlanjutan upaya melestarikan lingkungan melalui budaya.

\section{METODE}

Metode yang digunakan pada pelaksanaan kegiatan pengabdian ini adalah pertemuan langsung untuk penyampaian materi oleh narasumber kepada peserta edukasi. Adapun tahapan pelaksanaannya adalah: (1) FGD sosialisasi kegiatan kepada Ketua Kelompok PKK; (2) Memberikan edukasi tentang pentingnya upaya pelestarian budaya batik tulis; (3) Memberikan edukasi pemberdayaan ekonomi masyarakat terutama bagi ibu rumah tangga melalui ide usaha batik tulis.

Lokasi pelaksanaan kegiatan adalah di wilayah RT.14 RW.11 Desa Banjararum, Kecamatan Singosari, Kabupaten Malang. Waktu yang dipilih adalah pada hari libur (Minggu), pukul 15.30 WIB dengan pertimbangan hari dan jam tersebut peserta mempunyai waktu luang sehingga tidak mengganggu kegiatan rutin sehingga peserta dapat lebih focus terhadap materi yang disampaikan.

\section{HASIL DAN PEMBAHASAN}

Pelaksanaan pengabdian mengikuti tahapan yang telah disusun karena hal itu merupakan acuan dan sebagai petunjuk teknisnya. Secara umum mitra yang dipilih dalam kegiatan pengabdian ini cukup antusias menyambut ide yang disampaikan oleh tim pengabdi.

\section{FGD sosialisasi kegiatan}

Focus Grup Discussion (FGD) merupakan kegiatan awal yang dilakukan untuk pelaksanaan pengabdian ini. Pada FGD tim pengabdi berkordinasi dengan Ketua Kelompok PKK beserta pengurus PKK mengenai waktu pelaksanaan dan teknisnya. Sesuai yang disepakati awal bahwa bentuk kegiatannya adalah berupa edukasi kepada ibu-ibu anggota PKK dalam bentuk pemberian materi mengenai batik tulis khas Kabupaten Malang. Pelatihan batik tulis dapat dilakukan dengan menggunakan metode ceramah dan demonstrasi (Rahmanita \& Washinton, 2020).

\section{Memberikan Edukasi tentang Pelestarian Budaya Batik Tulis}

Salah satu upaya dalam rangka pelestarian batik tulis adalah dengan mengedukasi masyarakat melalui kegiatan sosialisasi maupun pelatihan. Pelatihan batik tulis seringkali dilaksanakan dalam rangka memberi pengetahuan baru maupun meningkatkan keterampilan yang telah dimiliki sebelumnya. 


\section{Pelestarian Budaya Lokal melalui Edukasi Pengenalan Batik Tulis Khas Kabupaten Malang bagi Kelompok PKK}

Aris Siswati, Alif Dewantara, Noeke Chrispur Madiarsih

Pendekatan pelatihan partisipatori dinilai efektif untuk meningkatkan keterampilan peserta baik pemula maupun pengrajin batik (Suliyanto, 2016).

Materi yang disampaikan pada kegiatan pelatihan bersumber pada buku Standar Operasional Batik Tulis yang telah disusun penulis (Gambar 1). Pemilihan dasar sumber materi merupakan hal penting karena bagi orang yang awam mengenai batik tulis, perlu mendapatkan wawasan yang jelas dan benar mengenai bagaimana sebuah batik tulis melalui tahapan-tahapan dalam pembuatannya. Hal ini akan mempengaruhi interpretasi peserta dan penilaian peserta terhadap sebuah hasil karya batik tulis.
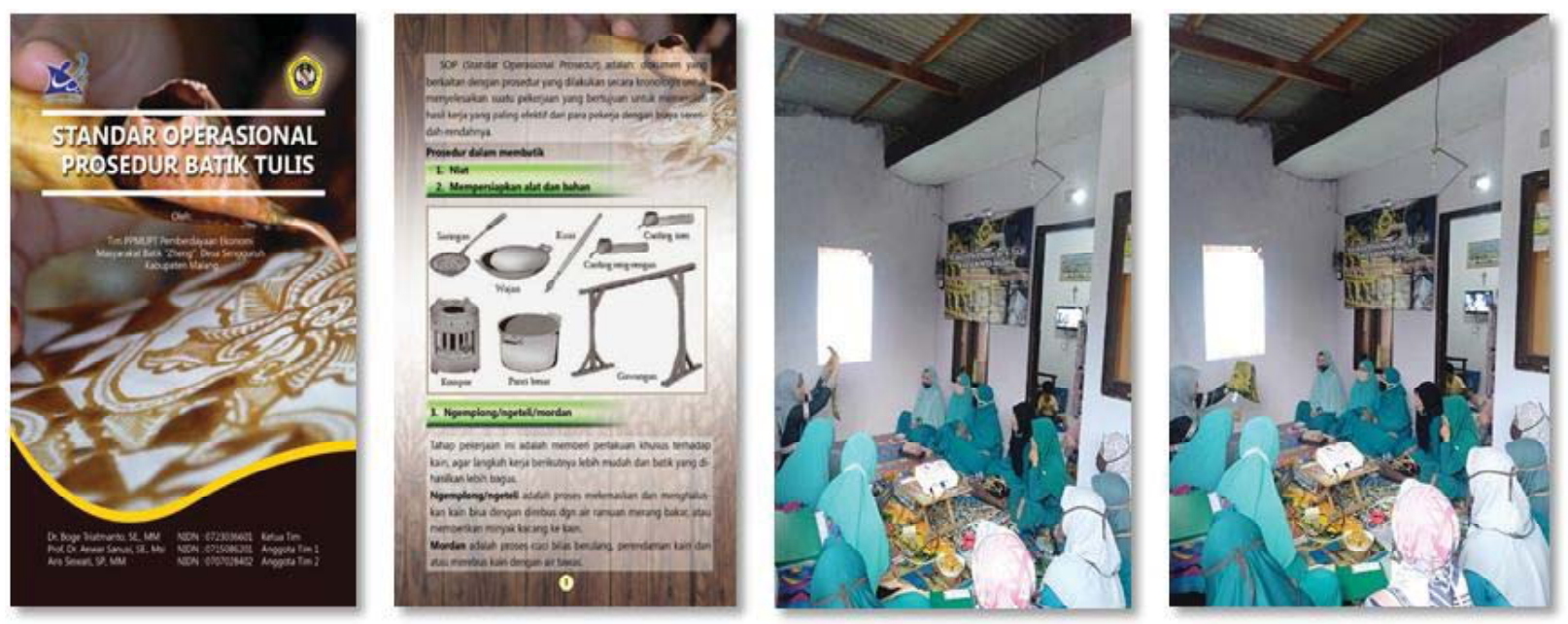

Gambar 1. Sumber Materi "Buku Standar Operasional Prosedur Batik Tulis" Gambar 2. Kegiatan edukasi batik tulis kepada mitra Kelompok PKK

Hasil dari transfer pengetahuan SOP batik tulis tersebut telah membuka wawasan dan memberi pemahaman terhadap peserta pelatihan mengenai value dari sebuah kain batik tulis, dimana sebuah batik tulis dihasilkan melalui tangan kreatif pengrajin yang tidak semua orang dapat membuatnya. Berbagai pendapat disampaikan oleh peserta pada evaluasi hasil kegiatan diantaranya peserta mendapatkan wawasan baru mengenai proses pembuatan batik tulis, peserta mendapat wawasan bagaimana mengenali kain batik, peserta mendapat wawasan mengenai corak dan motif batik khas Kabupaten Malang serta yang tidak kalah pentingnya adalah peserta memahami bahwa harga jual yang relatif mahal untuk sebuah batik tulis dinilai wajar mengingat proses yang dilakukan untuk menghasilkan kain tersebut juga tidak sederhana (Gambar 2).

\section{Memberikan Edukasi Pemberdayaan Ekonomi Masyarakat melalui Ide Usaha Batik Tulis}

Kegiatan pengabdian berbasis gender dapat dilakukan dengan pendekatan melalui kelompok PKK baik dalam bentuk pelatihan untuk meningkatkan pengetahuan dan keterampilan maupun pengelolaan usaha (Anggraeni et al., 2019). Kelompok PKK RT 14 Desa Banjararum, setiap bulan rutin mengagendakan kegiatan pembinaan bagi anggotanya. Salah satunya adalah dalam bentuk penyuluhan dan kegiatan keterampilan. Kegiatan pelatihan yang ditawarkan pengabdi disambut antusias oleh kelompok PKK, mengingat selama ini belum pernah ada edukasi bagi kelompok PKK mengenai batik tulis (Gambar 3 dan 4). 
ABDIMAS: Jurnal Pengabdian Masyarakat Universitas Merdeka Malang Volume 5, No 3, November 2020: 249-256
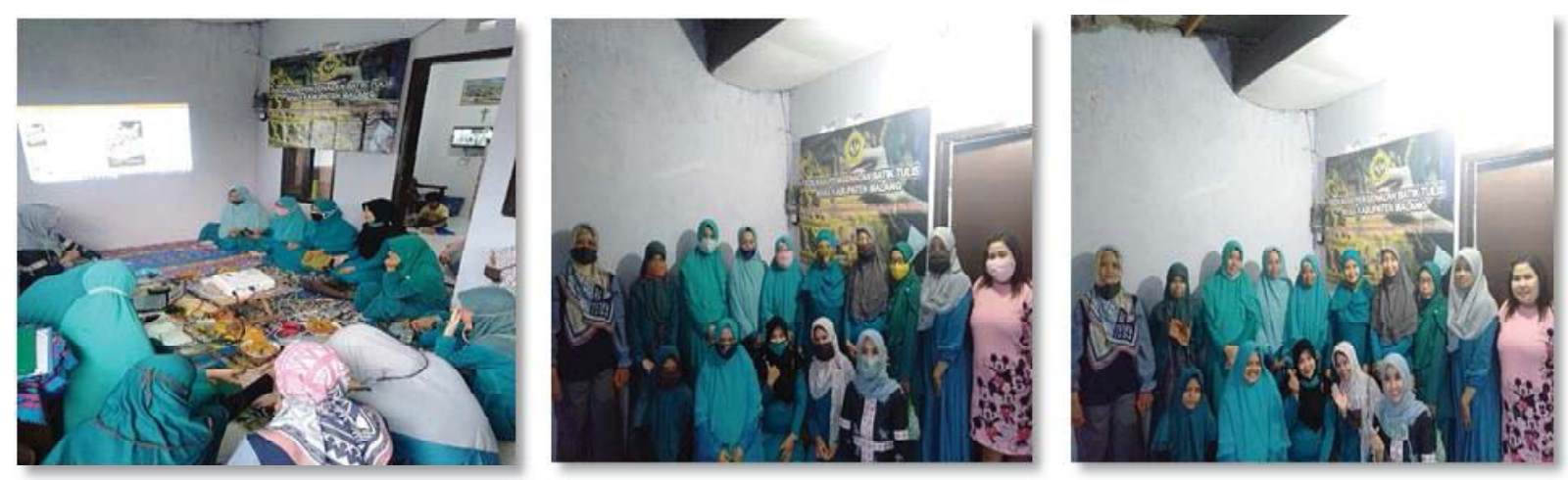

Gambar 3. Memberikan contoh batik tulis hasil karya UKM dari Ibu Rumah Tangga

Gambar 4. Pengabdi bersama peserta edukasi pengenalan batik tulis

Selain materi mengenai SOP pembuatan batik tulis, pengabdi juga memberikan wawasan bahwa batik tulis dapat dijadikan peluang untuk membuka usaha dengan memberikan contoh pengusahapengusaha batik tulis yang sebelumnya hanya sebagai ibu rumah tangga. Memberikan pengertian bahwa ketika Ibu Rumah Tangga (IRT) dapat menghasilkan pendapatan, maka IRT secara tidak langsung juga turut meningkatkan kesejahteraan keluarga dengan menambah income bagi rumah tangga. Hasil dari evaluasi setelah pelaksanaan kegiatan diketahui peserta belum ada yang tertarik untuk memulai usaha batik dengan pertimbangan bahwa peserta merasa perlu untuk mendapat pengetahuan yang lebih dalam termasuk juga praktik untuk membuat batik tulis sebelum memutuskan untuk merintis usaha pembuatan batik tulis.

\section{SIMPULAN DAN SARAN}

\section{Simpulan}

Pengabdian masyarakat merupakan salah satu bentuk kewajiban akademisi di Perguruan Tinggi. Implementasi kepakaran bidang ilmu dapat diterapkan dalam membantu masyarakat mencari solusi atas permasalahan sosial, budaya dan ekonomi. Pelestarian kebudayaan Indonesia merupakan tanggung jawab seluruh bangsa, dalam hal ini salah bentuk budaya tersebut adalah batik tulis yang merupakan kerajinan asli bangsa Indonesia. Masyarakat Indonesia sendiri yang harus berjuang mengupayakan lestarinya batik tulis. Edukasi mengenai batik tulis dilakukan dengan cara mensosialisasikan batik tulis baik mengenai sejarah, motif sampai dengan proses pembuatannya. Ibu-ibu kelompok PKK merupakan mitra potensial untuk turut serta mengupayakan pelestarian batik tulis. Dari hasil pengabdian yang telah dilaksanakan didapatkan hasil bahwa ibu-ibu kelompok PKK mendapat wawasan pengetahuan baru mengenai batik tulis dan menguatkan kebanggaan atas batik tulis Indonesia serta berkomitmen untuk mengembangkan pengetahuan yang didapat kearah yang lebih produktif.

\section{Saran}

Pelaksanaan kegiatan pengabdian ini mendapatkan respon yang sangat baik dari mitra, karena secara langsung memberikan manfaat kepada peserta sosialisasi. Sehingga mitra mengharapkan adanya 
keberlanjutan dari sosialisasi yang dilaksanakan yaitu dalam bentuk praktik pembuatan batik tulis. Hal ini menjadi keterbatasan di dalam pengabdian, dikarenakan kegiatan praktik akan membutuhkan persiapan yang lebih lengkap diantaranya penyediaan bahan dan alat praktik serta narasumber yang kompeten. Sehingga saran bagi pengabdi selanjutnya adalah supaya dapat memfasilitasi pelatihan praktik pembuatan batik tulis sehingga program yang dilaksanakan pengabdi merupakan kegiatan yang memang dibutuhkan oleh masyarakat.

\section{Ucapan Terima Kasih}

Ucapan terima kasih kami sampaikan kepada Pimpinan Universitas Merdeka Malang yang telah mendukung penyelenggaraan kegiatan pengabdian ini, dan kepada Mitra Ketua Kelompok PKK RT.14 RW.11, Desa Banjararum, Kecamatan Singosari, Kabupaten Malang atas kesediaan dan partisipasi aktif anggotanya untuk terselenggaranya kegiatan. Serta kami sampaikan juga ucapan terima kasih kepada UKM Batik Seng Desa Sengguruh, Kabupaten Malang yang menjadi inspirasi dalam kegiatan ini.

\section{DAFTAR PUSTAKA}

Andarwati, M., Subiyantoro, E., \& Subadyo, T. (2018). Pengaruh Pelatihan dan Penerapan Teknologi Tepat Guna (TTG) terhadap keberdayaan pengrajin batik tulis ramah lingkungan. Briliant: Jurnal Riset dan Konseptual, 3(3), 280-286. https://doi.org/10.28926/briliant.v3i3.189

Anggraeni, O. J., Kurniawati, D., \& Mastuti, L. (2019). Membangun wirausaha batik tulis berbasis gender pada Pengurus PKK di Kecamatan Kaliwates Kabupaten Jember. Seminar Nasional Hasil Pengabdian Masyarakat dan Penelitian Pranata Laboratorium Pendidikan Politeknik Negeri Jember.

Asy'ari, F. R., Nirwanto, N., \& Siswati, A. (2020). Pengaruh jumlah penduduk dan dana bagi hasil terhadap pajak daerah Kota Malang. Journal of Regional Economics Indonesia, 1(1). https://doi.org/10.26905/jrei.v1i1.4755

Falah, F. (2018). Estetika Batik Tulis Motif "Bintang Laut" Pekalongan, Jawa Tengah (Kajian Estetika). Nusa: Jurnal IImu Bahasa dan Sastra, 13(1), 16-25. https://doi.org/10.14710/nusa.13.1.16-25

Dwipasari, L., \& Subianto, T. (2018). Pendampingan pengembangan KUB (Kelompok Usaha Bersama) Batik Malangan di Kota Malang. Jurnal Pengabdian Masyarakat Universitas Merdeka Malang, 2(2), 42-50. https://doi.org/10.26905/abdimas.v2i2.1816

Jannah, S., Indrawati, I., Rahayu, H. D., Marwan, S., Najmuddin, M. K., Mufaiz, M. T., Dewantoro, A., Mega, K. I., Almukri, M. S., Suhermanto, A. Y., Hidayah, D. Z. M., \& Putri, M. R. (2020). Meningkatkan eksistensi dan pelestarian batik di era modern. Jurnal Pembelajaran Pemberdayaan Masyarakat, 1(2), 139-142. https://doi.org/10.33474/jp2m.v1i2.6536

Farida, L. L. (2017). Batik Tulis Sekar Jati sebagai identitas Kabupaten Jombang tahun 1993-2008. Avatara, $5(2)$.

Rahmanita, N., Washinton, R., \& Ranelis, R. (2020). Pemberdayaan ibu-ibu rumah tangga dan remaja putri melalui pelatihan batik tulis di Pusat Kegiatan Belajar Masyarakat (PKBM) AL-FATH. Jurnal Abdimas Mandiri, 4(1), 55-61. https://doi.org/10.36982/jam.v4i1.1046

Rahmadani, F. (2019). Motif batik kasih sayang ibu untuk memaknai hari ibu. Ikonik: Jurnal Seni dan Desain, 1(1), 7-12. 
ABDIMAS: Jurnal Pengabdian Masyarakat Universitas Merdeka Malang

Volume 5, No 3, November 2020: 249-256

Siswati, A. (2019). Eksperiental learning pelatihan financial life skills pada mahasiswa Universitas Merdeka Malang. Jurnal Bisnis dan Manajemen, 6(2), 81-87. https://doi.org/10.26905/jbm.v6i2.3673

Siswati, A., \& Prakoso, A. S. (2018). Impact of internal factors to entrepreneurship. Proceedings. $3^{\text {rd }}$ International Conference of Graduate School on Sustainability (ICGSS).

Suliyanto, S., Novandari, W., \& Setyawati, S. M. (2016). Efektifitas pelatihan partisipatori industri kreatif batik tulis. Jurnal Ekonomi dan Bisnis, 18(1), 139-148. https://doi.org/10.24914/jeb.v19i1.484

Triatmanto, B., Sanusi, A., \& Siswati, A. (2019). Pemberdayaan UKM Batik Seng Desa Sengguruh Kabupaten Malang. PEDULI: Jurnal Ilmiah Pengabdian Pada Masyarakat, 3(2), 37-47. https://doi.org/10.37303/peduli.v3i2.122

Wardani, L. K. (2014). Pengembangan kreativitas melalui pembelajaran batik bagi siswa Sekolah Dasar. Proceedings. Seminar Nasional Penguatan Eksistensi Karakter Generasi Bangsa Melalui Seni, 219-227. 